for such accommodation to be available for miners after a day's work? Dr. Williams stated that in his own area there was great progress in all forms of social life in connection with the various religious societies, and this had a profound effect on the social development of the district. He concluded by expressing his great indebtedness to a number of authorities and particularly to the work on "Pithead and Factory Baths," written by Messrs. Edgar L. Chappell and J. A. Lovat Fraser, after ten years' work in connection with the subject.

\section{THE PRESENT POSITION WITH RESPECT TO CANCER.}

BY

Oscar M. Holden, M.D., D.P.H., M.O.H., etc, County Borough of Dewsbury.

Cancer has for years past played a prominent part in the mortality rates for this country, and, indeed, for all countries having reliable methods of statistical compilation.

A perusal of the latest report of the RegistrarGeneral (1920) shows that for the first time Cancer claimed more deaths than Tuberculosis. The method in which this disquieting result has obtained is illustrated by the following table:-

\begin{tabular}{ccccc} 
Year. & \multicolumn{2}{c}{ Tuberculosis. } & \multicolumn{3}{c}{ Cancer. } & $\begin{array}{c}\text { Reneral Mortality } \\
\text { Rate. }\end{array}$ \\
1916 & $\ldots$ & 53,858 & 40,630 & 508,217 \\
1917 & $\ldots$ & 55,934 & 41,158 & $498,922^{*}$ \\
1918 & $\ldots$ & 58,073 & 41,227 & 611,861 \\
1919 & $\ldots$ & 46,312 & 42,144 & 504,203 \\
1920 & $\ldots$ & 42,545 & 43,687 & 466,130
\end{tabular}

The slow but steady increase in well shown, and I believe that improved diagnostic methods may be discounted inasmuch as there have been no noteworthy diagnostic advances in this subject during the past five years. During this same period the general mortality has dropped from 508,217 in 1916 to 466,130 in 1920 . The estimated civilian population covering these years remained nearly stationary, whilst it may be reasonably inferred that cancer is not a disease of the army population.

Cancer is essentially a cellular disease. The cancer cells are derived from the cells of the tissue involved, but, although the individual cells may be replicas of the normal cells of a particular tissue, their arrangement is abnormal and they bear certain embryonic characteristics.

The growth of cancer cells is unrestrained and appears independent of the factors governing the growth of normal tissues. The acquisition of the power of unrestrained growth seems to be a slow process and it is a property of the individual cell.

In this connection it is helpful to bear in mind certain facts. Cancer is a disease of tissues derived from the epiblastic layer of embryonic life. One of the functions of this tissue is protective, and it is in consequence subjected to wear and tear. This means an endowment of active proliferative powers. All chronic processes initiating cancer are attended by repeated destruction and repeated repair. There is evidence that the epithelial cells do undergo changes giving them embryonic characteristics in consequence of continual demands upon them for repairs. Processes creating the demand may, in consequence, be directly responsible for the origin of malignant growths.

The intercellular substance may have some influence in this matter. Champy in a series of experiments showed that epithelial cells grew in vitro in an even sheath without exhibiting specific arrangements, i.e., similar to the in vivo growth of cancer cells. Drew ${ }^{1}$ then demonstrated that these undifferentiated cells at once resumed their differentiation in vitro when connective tissue was added to them. This does not seem to be explicable upon a purely physical basis of different surface tensions.

Cells may be stimulated to growth by chemical means. The ova of frogs may be stimulated to multiplication, resulting in the formation of embryoes, by the addition of weak, or alkaline salts to the water in which they are kept. Muitiplication of plant tissues may be induced by the injection of similar chemicals; and, when such substances are applied continuously, the growth becomes continuous.

The especial attributes of the cancer cell are, firstly, its power of invasion; secondly, its powers of migration; and thirdly, its low vitality. Sir George Beatson ${ }^{2}$ in a recent paper has summed up, comprehensively, the accepted knowledge concerning cancer. He states that the following facts are acknowledged:-(1) The antiquity of the disease. (2) Its occurrence in all races of mankind. (3) The unequal susceptibility of different races. (4) Its existence in all vertebrates. (5) That the disease starts in a single cell which becomes possessed of great power of continuous and uncontrollable multiplication. (6) That the cell retains its parentage, always breeding true. (7) That it differentiates very little, and that irregularly. (8) That a periodicity of growth is common, and (9) That the development is neither 
purposeful or beneficial. It is sometimes argued against heading six that if this were so, how is it that squamous called carcinomata are found in regions where the normal cells are columnar. This is explainable by the alteration of the columnar cells by the wearing down process of continual irritation and consequent active proliferation until the originally highly specialised glandular cells lose their function and their attributes to become merely protective squamous cells, the secretive function being sacrificed solely for protection.

\section{Certain Theories of Cancer Formation.}

Parasitic Theory.

Butlin $^{3}$ believed that the cancer cell was an independent organism like a protozoon and that it lived as a parasite in the body. Professor Smith thinks that cancer in plants is due to a microorganism which can be isolated and cultivated and which produced cancer when inoculated upon healthy plants. No organism has been found in man which conforms with Koch's postulates.

This theory has now been almost wholly abandoned. The numerous inoculation experiments carried out in animals helped to bring this about, and it will be expedient to summarise a few of the findings and conclusions arrived at under this aspect of the problem.

Certain tumours are transplantable in animals, but different tumours vary in their power of successful transplantation. Also varying strains of mice do not exhibit the same susceptibility. Bashford, Murray and Cramer showed that a state of resistance can be acquired in animals after they have been inoculated with tumour material. It is now known that all tissues, especially those rich in cells, produce a limited degree of resistance to tumour growth when inoculated into animals of the same breed. Cancer cannot be transmitted from animals of one species to those of another.

It is essentially a disease of specific cells.

Mice in which a transplanted tumour had undergone spontaneous recovery could not be successfully re-inoculated. Bearing on this point, Chambers, Scott and Russ ${ }^{5}$ recently demonstrated that a degree of immunity may result from an adequate irradiation of a malignant growth, i.e., by destruction of cancer cells.

Briefly, the numerous inoculation experiments only appear to prove (1) That a tumour is inoculable in a certain percentage of cases and under certain conditions; (2) That inoculation takes place more readily in animals suffering from cancer than in healthy animals; (3) That there is developed a certain degree of immunity in animals who have recovered from inoculated cancer.

A conclusion to be inferred from the latter finding, but not yet proved, is that certain animals have a natural immunity or resistance to cancer, and by inference some human beings are more susceptible than others of the same race.

Irritation Theory.

This is perhaps the most promising single theory at the present, although it seems that the causation does not lie in one direction only. A combination of mechanical and obscure chemical factors is the possible exciting cause.

Under this theory I propose to divide known types of cancer, presumably caused by irritative processes, into three headings, following the classification of Wolbach ${ }^{6}$.

A.-Trade Processes.-Scrotal cancer in chimney sweeps is a classical instance. The epithelicinata of paraffin workers; workers in aniline oil and tar. In all, the evolution of the cancer is the same, namcly, a dermatitis, followed by warts, ulceration, cancer. In all the exciting cause is a constituent of coal tar. The epitheliomata of X-Ray workers is another type, with a different exciting cause, but with a similar clinical course.

B.-Cancer Due to Chronic Infective Processes.-Leukoplakia, a chronic proliferative inflammation of the tongue, is associated with a relatively high cancer incidence. The supervention of cancer upon lupus, cancer of the bladder following bilharziosis or vesical calculi; cancer of the gall-bladder accompanying or following gall stones are all well-known clinical instances.

C.-Cancer and Peculiar Habits.-Certain Kashmiri tribes (Never), in order to keep themselves warm, carry a small earthenware stone fixed round the abdomen. Cancer of the abdominal skin is very common in these people, but is very rare in other human races.

Cancer of the cheek is a rare disease of women, but it is common in the women of India. This may be due to the habit of betel-nut chewing. The nut is ground up with lime, made into a wad, and this wad is kept in one side of the mouth for days on end.

Cancer of the tongue, mouth and upper respiratory passages is far commoner in men than in women. Possibly this is due to the practice of smoking, which until recent years was a habit of the male sex. It will be interesting to see, in years to come, whether the female sex, following upon their emancipation, retain their favourable position in this respect. 
The Experimental Production of Cancer.

Cancer can be produced by long continued and repeated exposure to the X-Rays. Fibiger produced cancer in the stomach of rats by means of Spiroptera neoplastica (Cockroach worm). Yamagaya and Itchilkawa produced cancerous growth of a rabbit's ear by repeated applications of tarry substarces. It is curious that Murray failed to cause cancer by similar means in the rat.

As stated previously, an animal in which a tar cancer had been produced and the tumour successfully removed appeared to be insusceptible to the further application of tar, but was still susceptible to grafts of its own cancer. Cruickshank observed that two mice, which developed spontaneous mammary cancer, did not react to repeated and prolonged tar applications.

Germinal (Reproductive) Theory.

Sir George Beatson ${ }^{2}$ has recently profounded a theory which presents many interesting points. Deducing from the undoubted effect that removal of the ovaries has upon inoperable cancer of the breast; he believes that the sex glands have a powerful influence on the disease. He observes that the division of the nucleus of malignant cells closely resembles that found in developing reproductive tissue, and he thinks that the secretion of certain glands, usually dealt with by the testes and ovaries, is used by tissues which have retrograded physiologically, and so produces cellular growth typical of cancer. He surmises that the fat of the body might act as a middleman in the same way as the lymph does in ordinary nutrition. He also thinks that the pigmentary functions of cell life exert some action upon the reproduction of the cell. Pigmented moles are especially liable to take on malignant characteristics. These moles consist of groups of pigment forming cells identical with those occurring normally in some stages of development of the skin. Lister many years ago noticed that in inflammations the first changes were in the cell pigments. The fat in the neighbourhood of cancerous growths often shows abnormal pigmentation. Distinct support is given to this hypothesis when some of the predisposing causes of cancer are reviewed, e.g., age, the whitening of the hair, patches of cutaneous pigmentation all point to a migration and redistribution of body pigment. Chronic irritation marked by a cell proliferation is often accompanied by an increased deposit of pigment in the area.

In connection with the supposed part played by the body fat the following experimental findings are of interest.
Analysis of the fat of cancer patients showed chemical differences from normal fat in that there was an excess of non-saturated fatty acids. Shaw-Mackenzie ${ }^{8}$ found that the serum of blood taken from cases of cancer not only has an increased antitryptic value, but can accelerate the action of pancreatic lipase far more than normal serum. Sturrock9 showed that the average alkalinity of the blood serum in cancer cases was appreciably higher than in non-malignancy, whilst Mayo $^{10}$ observed that abdominal cancer appears only in an acid medium and that alkalinity retards cancer growth.

Another interesting item bearing upon this subject has been contributed by Ross. ${ }^{11}$ He found that the blood of a cancer patient, or the juice of a cancer, produced marked stimulating effects on leucocytes. Irritation causes cell death, and cell death liberates what he terms auxetic substances, i.e., augmentors of cell growth. In his opinion two factors are necessary for the production of a cancer: (1) The tissue in which it arises must be one in which katabolic changes predominate. (2) The presence of augmentors is required in the tissues.

To sum up briefly the views of a few of the great investigators into this baffing mystery.

Bashford, speaking at the International Congress of Medicine in 1913, looked upon cancer as an indirect result of chronic irritation. He was inclined to believe that the cause which led to proliferation and unbounded growth was some subtle chemical or biological agent.

Freund at the same discussion stated that normal blood contained a substance which was able to destroy cancer cells. He demonstrated that it was a fatty acid. He was of the opinion that chronic physical or toxic irritation produced a predisposition to cancer by destroying the normal fatty acids.

Lazarus Barlow, on the other hand, held that the etiology of cancer was inseparably associated with the radio-active content of the tissues, radio-active material being present in larger amounts in cancerous tumours than in normal cells.

Bond ${ }^{12}$ thinks that cancer must be regarded as an adaptive response on the part of certain cells or cell groups to environmental change and as the result of a process of variation and selection among the cells of the organism.

Sir George Beatson ${ }^{2}$ supposes that one of the conditions which keep cells from dividing is the integrity of its nucleus and of the protoplasmic contents, but if any chemical or physical reaction 
takes place in them their division of the cell may result and may continue indefinitely as the outcome of the permanent change in the nuclear pigment.

Jordon $^{13}$ follows Arbuthnot Lane and thinks cancer is to a large extent secondary to toxæmia of intestinal stasis.

Sites of Fatal Cancer Covering the Five YEARS, $1916-1920$.

\begin{tabular}{|c|c|c|c|c|c|c|}
\hline Lip & $\begin{array}{l}\text { Site. } \\
\ldots\end{array}$ & $\ldots$ & & $\begin{array}{l}\text { Male. } \\
1,213\end{array}$ & $\begin{array}{r}\text { Female. } \\
93\end{array}$ & $\begin{array}{l}\text { Total. } \\
1,306\end{array}$ \\
\hline Tongue & $\ldots$ & $\ldots$ & $\ldots$ & 5,440 & 567 & 6,007 \\
\hline Mouth & $\ldots$ & $\cdots$ & $\cdots$ & 2,919 & 377 & 3,296 \\
\hline Jaw & $\ldots$ & $\ldots$ & $\cdots$ & 2,530 & 859 & 3,389 \\
\hline Pharynx & & $\ldots$ & $\ldots$ & 1,133 & 359 & 1,492 \\
\hline Esophag & gus & $\ldots$ & $\ldots$ & 6,207 & 1,994 & 8,201 \\
\hline Stomach & \& Gall & 1 Bladd & der & 19,038 & 16,764 & 35,802 \\
\hline Liver & $\ldots$ & $\ldots$ & $\ldots$ & $* 9,428$ & ${ }^{*} 13,054$ & $* 22,482$ \\
\hline Mesenter & & $\ldots$ & $\ldots$ & 553 & 1,391 & 1,944 \\
\hline Intestines & & $\ldots$ & $\ldots$ & 10,156 & 14,110 & 24,266 \\
\hline Rectum & $\cdots$ & $\ldots$ & $\cdots$ & 9,743 & 7,326 & 17,069 \\
\hline Larynx & $\ldots$ & ... & ... & 2,686 & 782 & 3,468 \\
\hline Lung \& 1 & Pleura & $\ldots$ & .. & 1,340 & 803 & 2,143 \\
\hline Pancreas & & $\cdots$ & ... & 1,676 & 1,521 & 3,197 \\
\hline Kidneys & $\ldots$ & $\cdots$ & $\cdots$ & 902 & 798 & 1,700 \\
\hline Bladder & $\ldots$ & .. & $\ldots$ & 2,943 &, 204 & 4,147 \\
\hline Brain & $\ldots$ & $\ldots$ & $\cdots$ & 215 & 192 & 407 \\
\hline Bones (ne & ot jaw) & & $\ldots$ & 1,592 & 1,442 & 3,034 \\
\hline Prostate & $\ldots$ & $\ldots$ & $\cdots$ & 2,859 & - & 2,859 \\
\hline Testes & $\ldots$ & $\ldots$ & .. & 454 & - & 454 \\
\hline Skin (ine & luding & penis). & $\cdots$ & 3,347 & 2,150 & 5,497 \\
\hline Breast & $\ldots$ & $\ldots$ & $\ldots$ & 167 & 21,195 & 21,362 \\
\hline Ovary \& & Fallo & $\tan T u b e$ & es & - & 2,836 & 2,836 \\
\hline Uterus & $\ldots$ & $\ldots$ & $\ldots$ & - & 20,596 & 20,596 \\
\hline Vulva \& & Vagina & & $\ldots$ & - & 1,462 & 1,462 \\
\hline Other or & gans & $\ldots$ & ... & 3,005 & 2,173 & 5,178 \\
\hline Undefined & & $\cdots$ & 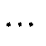 & 2,622 & 1,257 & 3,879 \\
\hline
\end{tabular}

In comparing the incidence of cancer upon different organs in the male and female respectively, it is found that there is a male preponderance for the lips, tongue, mouth, jaw, pharynx, cesophagus, skin (scretum), larynx, bladder, and slightly for the rectum, lung and pleura. A female preponderance is exhibited for the reproductive organs, breast, intestines, mesentery, liver and gall bladder. (As primary cancer of the liver is exceedingly rare, the seeming preponderance for this organ is probably due to secondary growths from the breast and reproductive organs.) The two sexes are about equal as regards the stomach, pancreas, kidneys, brain and bones (excluding the jaw).
Treub showed that the average age is higher with cancer of the body of the uterus than with cancer of the cervix. It is more frequent in married women, but less comparatively with cancer of the body of the uterus. Fibromas are more common in unmarried women. Uterine cancer is 100 per cent. more common in married than in unmarried women.

A consideration of these points leads us to the following conclusions :-

(1) Where the conditions are similar in both male and female, the incidence of cancer is about equal.

(2) Areas exposed to chronic irritation are the most usual seats of cancer.

(3) The excess of cancer in the male in the upper respiratory and alimentary regions is explainable to some extent by habits peculiar to males.

(4) Organs undergoing great involutive changes, or subjected to intermittent periods of great activity, are particularly liable to cancer.

Brownlee 14 , in a recent monograph, has shown that the mortality from cancer is higher in rural than in urban districts and that it increases from North to South. For practically all other lethal diseases the reverse is true. His conclusion is that the frequency of cancer is a function of senesence and that the cancer mortality at any age varies directly (under different conditions of environment in the same region) with the physiological age of the populations concerned.

Recent Austrian statistics show that waiters and public-house owners show a high mortality from cancer of the oesophagus-an interesting finding from the irritative theory view point. These same statistics indicated some evidence of a predisposition to cancer. The reappearance of cancer after a lapse of years, as sometimes occurs, is a support for this view. There is direct evidence that warts, burns, scars, etc., can be irritated to rapid growth and to degeneration by traumatism.

Williamson ${ }^{15}$ thinks that cancer is unaffected by environment. He points out that in by far the largest number the disease affects the alimentary tract and wonders whether present-day feeding exercises any influence.

Public Health Aspects.

In 1900 the cancer death-rate was 0.7 per 1,000 . In 1920 it had risen to 1.6 per 1,000. In spite of this no serious attempt has been made to grapple with the position. Sanitary measures have been 
confined to diseases known to be infectious or contagious, but little has been done for those, like cardiac disease or cancer, which do not manifestly appear to depend upon the element of contagion. Yet Public Health should concern itself with all causes affecting adversely the health and longevity of the people. The expectation of life for people over sixty has become less rather than more, in modern times, and cancer contributes an important quota towards the maintenance of this unsatisfactory position.

I submit that much can be done to lessen the cancer mortality. Trade cancers are preventable. Many cases of cancer of the lips, tongue and throat could be avoided by adequate universal dental treatment.

Again, cancer is a product of senility. This senility is not to be measured in years, but in the actual state of tissues and glands.

Tissues which first commence to atrophy are those most prone to cancer. Senility is brought about more rapidly under modern conditions than was formerly the case. The wear and tear of this restless age makes men young in years old in vitality. The psychology of the people is a great asset in furthering the public health. Enlightened authorities are coming to recognise that cheerful surroundings, recreation, adequate housing and intelligent nutrition are of the highest importance to the State. More and more are providing parks, recreation grounds and golf courses for their citizens. As cheerful surroundings in everyday life make for the maintenance of health, so does a hopeful temperament make for recovery from illness. The present pessimistic outlook of the ordinary citizen when confronted with the reality of cancer is detrimental. The need is for a better education of the public in the known facts of cancer. They should be brought to realise the bright side as well as the obverse; to learn that cancer in its early stages is curable; to learn the early signs by which they may know that the time has come to seek adequate medical assistance. The best method in. which this ought to be done is a matter for the various localities to decide upon themselves. Methods useful in towns might be futile in country districts.

An article in "Medical Science" for November, 1920, dealing with propaganda, said: " It is obvious that improved results in cancer cases can be brought about by increased knowledge on the part of the general practitioner, but he in turn depends on the patient. Patients come to hospital with growths as large and as inoperable as they did fifty years ago." It would be clearly neces- sary, in following this doctrine, to provide a sufficiency of hospital beds.

In 1921 the American Society for the control of cancer inaugurated a Cancer week. They held that such a week was justifiable upon two grounds: (1) The ignorance and indifference of individuals in regard to the early evidence of cancer. (2) The frequent lack of discrimination shown by persons in selecting the kind or cult of medicine for their treatment.

Cancer prevention is an individual matter. There is no evidence to support any infectiousness in the disease, although Ochsner ${ }^{16}$ thinks every precaution against cancer infection should be taken even though infectiousness has not been proved. The hereditary aspect is very problematical. He instances that the Japanese, who are scrupulously clean regarding their skin, are very free from external cancer, the reverse being true of the people of India. The factor of irritation would explain this, however.

Propaganda to be effective must aim at

(1) Educating the people at large in the early signs and in the vital necessity for earlier consultations.

(2) It should be continuous.

It must be realised that propaganda will not seriously reduce the incidence of cancer. That cannot be achieved until the cause is discovered. The most that can be hoped for is that in a certain number of cases life will be saved or at least prolonged for a number of years.

Tentative measures have already been put into operation in a few towns. Some years ago Dr. Mearns Fraser issued a pamphiet upon the subject. Recently Dr. Millard has followed suit in Leicester. The Cancer Research Fund of Ireland has issued a popular handbook and pamphlets upon the subject. Otherwise little has been done. Government Commissions are not altogether unmixed blessings, but it is surely time that a Commission should sit upon so important a question in order to sift the mass of evidence, experiments and other data now available, and to sum up in a concise and popular form the present position of the Cancer problem, and to suggest any measures practicable for its alleviation.

Medical Officers of Health, unfortunately, in many cases do not take sufficient interest in this problem. They argue that the cause is unknown and therefore nothing can be done to mitigate its ravages. Such an attitude of indifference, of fatalism, reacts unfavourably upon the public in all matters appertaining to the health of the people. It is our duty to give to the public such 
advice as is sound and proved. It is proved that early diagnosis and operation lessen mortality, and therefore the public-and by the public I mean the unreading and unthinking portion in particularmust be educated to comprehend this and urged to act upon it. Surely we are firstly practitioners of medicine, and secondly administrators, endeavouring to administer to the best advantage the knowledge gained by othere and by ourselves in the clinical branch of the profession.

\section{REFERENCES.}

1. "British Journal of Experimental Pathology," Vol. III., February, 1922.

2. "Lancet," 23rd September, 1922.

3. "Lancet," 25th November, 1911, and 2nd December, 1911.

4. Third, fourth and fifth Scientific Reports of the Imperial Cancer Research Fund, 1908, 1911 and 1912.

5. "Lancet," 4th February, 1922.

6. "New Growths and Cancer," Harvard Health Talks, No. 10.

7. “ British Medical Journal," 3rd September, 1910.

8. “"Medical Press and Circular," 1912, I., 643.

9. “'British Medical Journal," 1913, Vol. II., p. 780.

10. Mayo Clinics, 1918.

11. "Induced Cell Reproduction and Cancer," 1910 .

12. “'Lancet,"' 1911, Vol. II., p. 349.

13. “ British Medical Journal," 1920, Vol. II., p. 959 .

14. "The Use of Death Rates as a Measure of Hygienic Conditions," 1922.

15. Report of M.O.H., Edinburgh, 1921.

16. “Ann. of Surgery,"' 1921, March, p. 294.

\section{METHODS OF INFANT FEEDING.}

\section{BY}

William J. Cox, M.B., Ch.B., D.P.H. (M.O.H. for the Borough of Watford).

The subject of infant feeding which we are considering is a vast one, and it is for this reason that I am dealing with only some of the methods employed.

Obviously the first method to consider is Nature's method, or breast feeding. In any actual case of infant feeding no consideration of other methods can for a moment be entertained until the possibilities of breast feeding have been fully explored.

In this paper, however, I shall devote comparatively little space to the consideration of the subject of breast feeding.
This is merely for the reason that I can say little about this subject which will be of interest to you, or new to you, but I feel sure that you will acquit me of any desire to minimise the importance of it. I must, in passing, refer to the valuable service done to the cause of breast feeding by its great advocate, Dr. Truby King, and also to the useful practical work in breast feeding which is being done at the home he has founded, where the restoration of breast feeding has in many cases been accomplished many weeks after its abandonment. Also the entire feeding of triplets at the breast is quite easily attained in this institution, being in fact practised there whenever the opportunity arises.

Budin laid down as a rule at his clinic that every woman must suckle her infant while in hospital. It has indeed been found that nearly 100 per cent. of mothers are able to suckle their infants whilst lying-in at a hospital.

Mothers are less successful in their own homes during the first fortnight of lactation than in hospital, presumably owing to the fact of less favourable environment caused by the proximity of household worries.

Various reasons are given for the failure of breast feeding when the mother leaves her bed and gets up. Amongst these is the ingenious suggestion that the infant for a time is less vigorous, owing to deprivation of the heat from its mother's body which in many cases it enjoys whilst the mother is in bed, in spite of advice against this practice by Health Visitors. Being less vigorous it docs not stimulate the breasts with its usual vim, with the result that breast milk tends to fail.

From whatever cause, there is undoubtedly a large percentage of failures in breast feeding, not only among the working classes, but also among the middle classes, who perhaps more frequently fail in this natural duty to their offspring than the poorer classes of mother.

Among the middle classes, too, little use is made of partial breast feeding. It is quite common for the working class mother to give breast feeds only at night, or night and morning, in addition to artificial feeding. Sometimes this practice is kept up for a long period, often much longer than twelve months, and provided that an abundance of other suitable food is given there can be no harm in this practice.

An infant will not develop rickets from being kept on the breast too long, unless there is an insufficient supply of other foods. Further, every ounce of breast milk which the infant obtains is 